\title{
Photoreceptor degeneration and choroidal neovascularization in aged BALB/c mice following systemic neonatal murine cytomegalovirus infection
}

\author{
Jinxian Xu \\ Augusta University \\ Xinglou Liu \\ Augusta University \\ Xinyan Zhang \\ Augusta University

\section{Brendan Marshall}

Augusta University https://orcid.org/0000-0001-7147-0075

\section{Zheng Dong}

Augusta University https://orcid.org/0000-0003-3538-8095

\section{Sylvia Smith}

Augusta University

\section{Diego Espinosa-Heidmann}

Augusta University

Ming Zhang ( $\triangle$ mzhang@augusta.edu )

Augusta University https://orcid.org/0000-0002-4012-3932

\section{Article}

Keywords: cytomegalovirus, age-related macular degeneration, choroidal neovascularization, latency, inflammation, complement, blood retinal barrier

Posted Date: September 10th, 2020

DOI: https://doi.org/10.21203/rs.3.rs-70314/v1

License: (c) (1) This work is licensed under a Creative Commons Attribution 4.0 International License. Read Full License 


\section{Abstract}

Age-related macular degeneration (AMD) represents a leading cause of irreversible visual dysfunction in older individuals but its genesis is poorly understood. Human cytomegalovirus (HCMV), which infects 50 to $80 \%$ of humans, is usually acquired during early life and persists in a latent state for the life of the individual. Here we show that systemic neonatal murine cytomegalovirus (MCMV) infection of BALB/C mice resulted in dissemination of virus to the eye where it localized to choroidal endothelial cells and RPE cells. MCMV underwent ocular latency in all neonatally infected mice and latent/persistent ocular infection was associated with expression of MCMV immediate early genes, significant upregulation of several inflammatory/angiogenic factors. AMD-like pathology, including basal lamina deposits (BLamD), subretinal drusenoid deposits (SDD), severe photoreceptor degeneration, choroidal neovascularization (CNV) develop in eyes of latently-infected aged mice. Our study suggests a possible viral etiology for AMD as a result of latent/persistent ocular CMV infection.

\section{Introduction}

Age-related macular degeneration (AMD) is a complex, multifactorial, progressive disease, which is the leading cause of irreversible visual dysfunction in older individuals $\mathrm{s}^{1-3}$. The disease is characterized in its early stages by lipoprotein deposits at the basal and apical aspects of the RPE and in its advanced forms by choroidal neovascularization (CNV) ${ }^{1,2}$ or geographic atrophy (GA) of the outer retinal tissue, retinal pigment epithelium (RPE) and choriocapillaris ${ }^{4-6}$.

Human cytomegalovirus (HCMV) is a ubiquitous beta-herpesvirus, which infects 40 to $80 \%$ of individuals in the human population 7 . CMV persists for the life of the host through cycles of latency and reactivation following primary infection ${ }^{8}$. The establishment of CMV latency can occur in multiple sites and cell types in the host, including endothelial cells and hematopoietic cells ${ }^{9}$. HCMV is usually acquired during early life, with the incidence of congenital infection ranging from $0.5-2.4 \%$ of all live births ${ }^{10-12}$. More than $12 \%$ of 1 year old U.S. infants are infected with $\mathrm{HCMV}^{13}$. Since the innate and adaptive immune systems are not fully mature during early life ${ }^{14}$, acquiring HCMV infection during this period could lead to widespread virus dissemination throughout the body, resulting in viral latency in a number of sites including the eye. Indeed, the eye is one of the major target organs of congenital HCMV infections with the incidence of HCMV chorioretinitis reported to be $25 \%$ in infants with symptomatic congenital HCMV infection ${ }^{10,15-17}$. Although only about $1 \%$ of infants who are asymptomatic and congenitally infected have CMV chorioretinitis ${ }^{10,15-17}, \mathrm{CMV}$ could spread to and become latent in the eye in significantly more asymptomatic infants without chorioretinitis. Indeed, recent studies in our laboratory of ocular tissue from human cadavers, revealed that HCMV DNA was present in 4 of 24 choroid/RPE samples, suggesting that choroid/RPE might be a site of HCMV latency ${ }^{18}$.

HCMV infection might be a novel risk factor for the progression of AMD since there is a significant association between elevated anti-HCMV IgG titers and neovascular AMD compared to either dry AMD or 
non-AMD controls ${ }^{19}$. The cytomegaloviruses (CMVs) are species-specific and murine cytomegalovirus (MCMV) infection of mice is widely used to mimic human diseases. By using MCMV resistant black mice, previous studies from Cousins et $\mathrm{al}^{20}$ as well as from our own laboratory ${ }^{18}$ have shown that MCMV exacerbates the development of CNV in both a laser-induced CNV mode ${ }^{20}$ as well as in a VEGFoverexpressing mode ${ }^{18}$. In the studies presented herein, we demonstrate for the first time that latent ocular infection is associated with the development of advanced AMD, including severe photoreceptor degeneration and CNV in aged, MCMV-infected BALB/c mice.

\section{Results}

MCMV disseminates to the eye following systemic infection of neonatal mice. To test our hypothesis that acquiring cytomegalovirus infection early in life results in widespread dissemination of virus to several sites including the eye, 50 pfu of MCMV were injected i.p. into BALB/c mice at either < 3 days, 1 week, 2 weeks or 6 weeks after birth. All mice, including newborns, survived viral infection and appeared healthy. At day 14 post infection (p.i.), as shown in Figure 1A, virus recovery was higher in mice infected with MCMV soon after birth, with replicating virus recovered from eyes of all mice infected as newborns. However in mice infected with MCMV at 6 weeks of age, no replicating virus could be detected. MCMV DNA was detected in eyes of all mice which were infected with MCMV at or before 2 weeks of age (26 of 26 eyes) whereas MCMV DNA was detected in only 2 of 6 eyes of mice which were infected with MCMV at 6 weeks of age ( $<0.0001$, Chi-square test). Not surprisingly, MCMV was recovered from salivary glands and lungs in all 4 groups of mice which were infected with MCMV during the time interval $<3$ days to 6 weeks after birth (Figure 1A).

To investigate the exact ocular localization of MCMV in mice infected at $<3$ days after birth, eyes were immunostained with both anti-MCMV EA and anti-RPE65. We observed that the majority of MCMV infected cells were located in the choroid (Figure 1B, Table 1). A few MCMV infected cells were also observed in the RPE layer (Figure 1B, indicated by arrow). In addition, virus-infected cells were also occasionally observed in anterior segments including the iris and ciliary body (Table 1). No MCMVEA positive cells were observed in the inner retina (Figure 1B). A small number of infiltrating cells were observed in the subretina/photoreceptor layer of 2 weeks-old uninfected control eyes, but significantly more were observed in the photoreceptor layer of MCMV-infected mice of the same age (supplemental table 1). These cells did not stain with either anti-RPE-65 or anti-MCMV EA (Figure 1B, indicated by arrow heads). Although some infiltrating cells in the photoreceptor layer of MCMV-infected mice stained positive for CD45 (Figure 1C), these cells stained negative for several immune markers including lba1(Figure 1D), CD11b (Figure 1C), DX-5 (not shown), and CD11C (not shown) indicating that these cells were most likely not systemic immune cells. Of note, significantly more CD45 positive cells were observed in the choroid of MCMV-infected mice than in the choroid of age matched control mice (Supplemental Table 1). H\& E staining also showed some infiltrating cells in the photoreceptor layer (Figure 1F). However, no remarkable pathological changes were observed in the inner retina (Figure 1F). To investigate more closely the localization of MCMV in the eye, infected ocular tissue was examined 
electron microscopically following immunogold staining with anti-MCMV EA. These experiments showed that immunogold-labeled MCMV EA was present in the nuclei of some vascular endothelial cells (Figure $1 \mathrm{G}$ ) and pericytes (Figure 1H) in the choriocapillaris, and also in sporadic RPE cells (Figure 1I).

Electron microscopical analysis was used to determine if MCMV infection in the choroid and RPE was associated with a compromised blood-retina barrier and/or pathological changes in the inner retina. As shown in Supplemental Figure 2, the outer blood-retina barrier (BRB) appeared to be intact and Bruch's membrane showed no remarkable disorganization or disruption when viewed electron microscopically. While the majority of RPE cells in infected mice were indistinguishable from RPE cells in uninfected control mice, large vesicles were noted in occasional RPE cells while increased phagocytosis of outer segments (OS) was also observed. Neither cell death nor any remarkable infiltration were found in the inner retina of MCMV-infected mice although a few infiltrating cells were observed in the photoreceptor layer.

Ocular MCMV infection becomes latent in choroid and RPE. To determine if MCMV infection undergoes latency in the eye and extraocular organs/tissues following systemic infection, 50 pfu of MCMV were injected i.p. into BALB/c mice at either $<3$ days, 1 week, 2 weeks or 6 weeks after birth. Mice were sacrificed at 3 months p.i. and tissue samples were collected. No replication competent MCMV could be recovered from eyes, lungs or salivary glands at this time. Nevertheless, MCMV DNA was still present in eyes of mice infected during early life and was detected in 9 of 9 eyes of mice infected at $<3$ days after birth and 5 of 8 eyes of mice which were infected at 1 week of age. However, when mice were infected with MCMV at 2 weeks of age, MCMV DNA was presented in only 2 of 10 eyes. No MCMV DNA was detected in eyes of mice which were infected at 6 weeks of age. In contrast, MCMV DNA was present in the lungs of all mice, irrespective of time of infection.

Significantly more infiltrating cells were observed in the choroid and photoreceptor layer during acute infection (Supplemental Table 1). To determine if these infiltrating cells were still present in the photoreceptor layer and choroid during latency, eyes were collected 4 months post neonatal infection and immunostained with anti-CD45. As shown in Supplemental Table 1, there were no significant differences in the numbers of infiltrating cells between MCMV-latently infected eyes and age matched uninfected controls, although the number of CD45+ cells was slightly elevated in choroids of latently infected mice $(5.20 \pm 3.96)$ compared to uninfected controls $(1.60 \pm 1.52)$.

Since MCMV infected cells was mainly observed in the choroid (Figure 1B), posterior eyecup cultures were employed to determine if latent ocular MCMV could be reactivated in vitro. Eyes were collected at 4 months p.i. Posterior eyecups, consisting of sclera, choroid, and RPE, were separated and cultured at $37^{\circ} \mathrm{C}$. Culture medium was collected bi-weekly and assayed by plaque assay for replicating virus. Posterior eye cup cultures began to produce replicating virus beginning at day 7 of culture (2/12 positive) while at day 14 of culture. 8 of 12 eye cup cultures produced replicating virus. Following 3 weeks in culture, virus was detected in 11 of 12 samples. To identify the location of the reactivated virus in vitro, eye cup cultures were stained for MCMV EA antigen. This showed that MCMV EA was present in sclera 
and choroid, and also co-localized with some RPE-65 positive RPE cells (Figure 2A). In addition, we separated RPE cells and choroid from posterior eyecups of MCMV latently infected mice according to a protocol described previously ${ }^{21}$ and performed PCR to detect MCMV DNA. These experiments indicated that MCMV DNA was present in both RPE cells (4/4) and choroid (4/4).

Virus reactivation in latently infected eyes following systemic immunosuppression. Our previous studies have shown that latent virus can be reactivated from infected eyes by deeply systemic immunosuppression several months after MCMV intraocular inoculation ${ }^{22}$. To determine if latent MCMV could be reactivated in eyes of neonatally infected mice by immunosuppression in vivo, newborn BALB/c mice were inoculated i.p. with 50 pfu of MCMV and 4 months later, Some mice were deeply immunosuppressed with methylprednisolone plus anti-T cell antibodies, which depleted more than $99 \%$ of CD 4 and CD8 T cells as previously described ${ }^{22,23}$. After 2 weeks, eyes and extraocular organs were collected and analysed by plaque assay. This showed that no replicating virus was present in eyes or extraocular tissues, including salivary glands and lungs, of any latently infected immunocompetent mice. In contrast, replicating MCMV was recovered from 6 of 8 eyes of immunosuppressed mice and also from the majority of extraocular tissues (Figure 2B). Although significantly more replicating virus was recovered from lungs and salivary glands compared to eyes during acute infection (Figure 1A), a surprisingly similar amount of replicating virus was recovered from eyes and salivary glands or lungs during reactivation by immunosuppression (Figure 2B).

In order to assay for the presence of virus in leukocytes, DNA and total RNA were isolated from white blood cells of the two groups of mice. Expression of the MCMV IE1 and GB genes were analyzed by real time RT-PCR while PCR was used to test for the presence of virus DNA. Although no MCMV DNA was detectable in the blood of non-immunosuppressed, latently infected mice (0/6), MCMV DNA was detected in leukocytes in 5 of 8 immunosuppressed mice. No MCMV IE1 or GB transcripts were detectable in any blood samples from either immunosuppressed or non-immunosuppressed latently infected mice.

To identify the ocular location of MCMV reactivation, we performed antibody staining with both antiMCMV EA and anti-RPE-65. As previously observed during acute infection (Table 1), MCMV-infected cells were present in the choroid of all eyes (6/6) and in RPE cells of some eyes (3/6) (Table 1, Figure 2C). No virus was detected in the inner retina, although virus-infected cells were observed in anterior segments including the iris and ciliary bodies of 6 of 6 mice (Figure 2D), compared to only 1 of 7 mice during acute infection (Table 1). This suggests that reactivated MCMV might spread from the choroid to the ciliary body and iris via the uveal tract. $\mathrm{H} \& \mathrm{E}$ staining showed no remarkable pathological changes in the inner retina (Figure 2E, 2F, 2G).

\section{AMD-like pathology by Spectral-Domain Optical coherence tomography (SD-OCT). SD-OCT is a} noninvasive imaging technique, providing high-resolution, cross-sectional images of the retinal microstructure in vivo ${ }^{24,25}$. By using the Envisu R2210 system of Leica Microsystems, SD-OCT examinations were performed and the retinal thickness was measured in eyes of MCMV latently infected mice and eyes of age matched controls at 4,8 and 18 months p.i. (Figure $3 A$ ). Whereas no remarkable 
pathological changes were detected by SD-OCT in eyes of MCMV latently infected mice at 4 months p.i., the mean retinal thickness was significantly lower in eyes of latently infected mice, compared to agematched control eyes, beginning at 8 months p.i., as shown in Figure 3B. In control mice, mean retinal thickness deteriorated with age and was lower in eyes of control BALB/c mice at 18 months of age compared to control mice at 8 months of age. However, apart from changes in retinal thickness, no other remarkable pathological changes were detected by SD-OCT in eyes of MCMV latently infected mice at 8 months p.i. or in control eyes at all ages. In contrast, besides significantly lower retinal thickness in all 40 eyes examined, as shown in Figure 3A, severe photoreceptor degeneration, including disappearance of the entire outer nuclear layer (ONL) in some areas, was observed in 21 eyes at 18 months p.i. Other pathological changes observed in these 21 eyes included CNV-like lesions (average 2 per eye) (Figure 2C) and retinal detachment (not shown), which were noted in 6 and 4 eyes respectively. Eyes with CNV-like lesions were removed, sectioned and stained with anti-CD31 and isolectin. The results confirmed the presence of CNV lesions in the photoreceptor layer (Figure 3D, 3E).

AMD-like pathology by electron microscopy (EM). To more precisely define the types of pathological changes which are associated with latent MCMV infection of the choroid and RPE, eyes were collected from latently infected BALB/c mice at 4,8 and 18 months p.i. as well as from age-matched, uninfected controls and processed for examination by EM. This revealed the presence of various pathologies in all 11 eyes from MCMV latently infected mice at 4 (3 eyes), 8 ( 3 eyes) and 18 (5 eyes) months p.i.

Specifically, at 4 months p.i., many large lipid vesicles were observed inside RPE cells as shown in Supplemental Figure 3D. Lipid vesicles were also noted in Bruch's membrane (BM) (Supplemental Figure 3B, 3C), which appeared to be thickened (Supplemental Figure 3B) and darkly stained in some areas (Supplemental Figure 3D, 3E). Although platelets were occasionally observed in the choriocapillaris of age-matched uninfected control eyes, more were observed in eyes of MCMV latently infected mice at 4 months p.i. Platelets were attached to vascular endothelia in the choroid and appeared activated (Supplemental Figure 3F, 3G, 3H), while cell death was also noted in some areas of the choroid (Supplemental Figure 3E). However, the defining pathologies which are the hallmark of AMD, such as basal lamina deposits (BlamD) and photoreceptor degeneration, were not observed at this time point.

At 8 months p.i., many large lipid vesicles were still present inside some RPE cells (Figure 4B, arrows), while only occasional lipid vesicles were noted in RPE cells of control eyes (Figure 4A). Although lipid vesicles were not noted in $\mathrm{BM}, \mathrm{BlamD}$ deposits were now present in some areas between the plasma membrane and basal lamina of the RPE (Figure 4B, 4C, 4E, 4H) in 3 of 3 eyes from MCMV latently infected mice at this time point. The majority of BlamD deposits were stained lightly $(4 \mathrm{~B}, 4 \mathrm{C}, 4 \mathrm{E}, 4 \mathrm{H})$, although a few were dark-stained (not shown). As shown in Figures $4 \mathrm{C}$ and $4 \mathrm{D}$, there was a loss of tight junctions between some RPE cells located below the BlamD, with evacuated areas created between these RPE cells. In addition, some RPE cells appeared atypical and exhibited marked vacuolization (Figure 4F, $4 G$ ). In the subretinal space near these atypical RPE cells, we observed large structures, which were separated by an intact septum or membrane (Figure 4F, indicated by star) and which contained heterogeneous material, including dark-staining OS-like fragments (Figure 4F, indicated by arrow heads). 
The morphology of nearby photoreceptors was disturbed, with shortening and loss of outer segments (Figure 4F, indicated by arrows). Although the identity of this structure is uncertain, it may be a large phagolysosome or a subretinal drusenoid deposit (SDD) separated by an intact septum. SDD was recently recognized as another type of extracellular lesion located in the subretinal space of AMD eyes ${ }^{26-}$ 28. A few infiltrating cells were observed in the subretinal space of infected (Figure $4 \mathrm{H}, 4 \mathrm{I}$, indicated by arrows) and control mice (not shown) at 8 months p.i. while, dark-staining OS-like fragments were observed inside some infiltrating cells of infected mice. As shown in Figure 4J, discs were occasionally noted in these fragments.

At 18 months p.i., 5 eyes from infected mice, including 1 eye with severe photoreceptor degeneration and CNV-like lesions identified by SD-OCT, as well as 3 eyes from age matched, uninfected control mice, were removed and processed for electron micrsocopy. Large lipid vesicles were present in some RPE cells of eyes of 18 month old uninfected mice (Figure $5 \mathrm{~A}$ ) and a few infiltrating cells were also observed in the subretinal space of these mice (Figure 5A, indicated by arrow head). In addition, loss or shortening of OS was sometimes noted (Figure 5B). However, no other pathologies, such as BlamD or SDD were observed in any of the 3 control eyes examined.

In eyes of MCMV-infected 18 month old mice, infiltrating cells were sometimes observed in the subretina while dark-staining OS-like fragments were also observed inside some of these cells (Figure 5C, 5D). As shown in Figure 5G, BlamD deposits were observed in 4 of 5 eyes examined. Some SDD-like structures were noted in the subretinal space of all 5 eyes of MCMV-infected mice. (Figure 5F, 5G, 5H) and although some were well formed, these structures are apparently not cellular vesicles since they were not separated by an intact septum or membrane. Some deposits contained dark-staining OS-like fragments (Figure 5F, $5 \mathrm{H}$, indicated by arrows), while others appeared drusen-like and were lightly stained. The morphology of nearby photoreceptors was disturbed, with shortening and loss of OS and IS (Figure 5F, indicated by arrow heads), while in some areas, OS were completely absent with SDD deposits extending into the IS layer (Figure 5F, indicated by star). Some photoreceptors appeared apoptotic, with nuclear shrinkage and strong chromatin condensation. (Figure 5E). In addition, a few ectopic photoreceptor nuclei were noted in the IS and OS layers (Figure 5I) while large lipid vesicles were occasionally observed inside RPE cells of MCMV-infected mice (Figure 5C). Thinned and disrupted RPE structure was observed adjacent to areas of SDD (Figure 5H) and some RPE cells exhibited marked vacuolization (Figure 5E). Extensive choroidal platelet infiltration both within choroidal capillaries and in perivascular tissue (Figure $5 \mathrm{~J}$ ) was observed in 5 of 5 eyes examined. One particularly striking abnormality was the presence of relatively large arteries in some areas of the choroid. An example is shown in Figure $5 \mathrm{~K}$, with a large artery located between the sclera and Bruch's membrane although no capillaries were observed in this region. .

The presence of CNV lesions and severe retinal degeneration was observed in one eye and confirmed by electron microcopy (Figure 5M, 5N). As shown in Figure 5M, new blood vessels were noted in the sub-RPE space, suggesting that their origin was choroidal rather than retinal although the RPE in this area was located adjacent to the innernuclear layer (INL) due to the loss of the entire ONL (Figure 5M). Severe retinal degeneration was not confined to areas of CNV and was also observed in non-CNV areas of the 
retina. As shown in Figure 5L, no ONL is present while the INL is reduced in size and composed of only 3 to 4 layers of cells.

Expression of MCMV immediate early genes and host inflammatory/angiogenic factors. Cytomegalovirus latent infection could result in expression of a number of virus encoded proteins with the potential to significantly alter homeostasis of the latently infected cell and the surrounding cellular environment ${ }^{29}$. Therefore, expression of the MCMV IE1, IE3 (immediate early genes) and gB (a late gene) genes was analyzed by real-time RT-PCR using RNA isolated from eyes of latently infected BALB/c mice at 4, 8 and 18 months p.i. As shown in Table 2, expression of MCMV IE gene transcripts was detected in the majority of eyes from latently infected BALB/c mice at all 3 time points. In contrast, expression of transcripts from the $\mathrm{gB}$ late gene was detected only rarely in latently infected eyes. No replicating virus was detected by plaque assay in any eyes of latently infected mice at 4,8 or 18 months p.i.

CMVs have been shown to induce angiogenesis via the production of various angiogenic factors ${ }^{30}$ including cytokines/chemokines such as IL $6^{31,32}$ and $\operatorname{CCL} 5^{33}$ and growth factors such as angiopoietin ${ }^{34}, \mathrm{VEGF}^{35}, \mathrm{TGF}^{-}{ }^{34}$, and M-CSF ${ }^{34}$. Although IE proteins alone are not sufficient to drive viral genome synthesis or production of infectious viral progeny in infected cells ${ }^{36}$, they can influence the cellular environment ${ }^{37}$ and previous studies have suggested that IE1 alone can trigger a proinflammatory host transcriptional response via a STAT1-dependent mechanism ${ }^{38,39}$. Since latent ocular infection results in expression of viral IE genes, we hypothesized that expression of some inflammatory factors and growth factors might also be stimulated by latent ocular MCMV infection. Therefore, real time RT-PCR was used to test for expression of these genes in latently infected and control eyes.

We observed that transcript levels of several cytokines and growth factors, particularly CCL5, were strongly upregulated in latently infected eyes compared to age matched control eyes (Table 3). At 4 months p.i., the relative levels of CCL5, angiopoietin I and TGF- $\beta 1$ transcripts were more than 10 times higher than in control, uninfected eyes while overall 9 of 11 gene transcripts studied were upregulated in latently infected eyes. By 8 months p.i., levels of CCL5 gene transcripts remained elevated, while mRNA levels of the other inflammatory factors and growth factors had returned to levels similar to those of controls. By 18 months p.i., CCL5 levels were still elevated, while IL6 transcripts were approximately 27fold higher relative to controls.

To determine if elevated transcript levels were associated with increased protein expression, relative protein levels of CCL5, angiopoietin I, TGF- $\beta 1$ and its receptors, as well as IE6 and VEGF were measured by ELISA or western blot. At 4 months p.i, relative protein levels of angiopoietin I (Figure 6C, 6D) and CCL5 (Figure $7 \mathrm{H}$ ) were significantly increased in latently infected eyes compared to age-matched controls. Although relative levels of the $45 \mathrm{KD}$ inactive form of TGF- $\beta 1$ (Figure 6A, 6B) and TGF- $\beta$ receptors including TGF- $\beta$ R1 and TGF- $\beta$ R2 (Figure 6C, 6D) were significantly increased in eyes of latently infected mice at 4 months p.i., surprisingly, protein levels of the active forms of TGF- $\beta 1$ including both the $25 \mathrm{KD}$ dimer and 12KD monomer (Figure 6A, 6B) were significantly lower in latently infected eyes compared to age-matched control eyes. By 8 months p.i., protein level of CCL5 remained significantly elevated in eyes 
of latently infected mice (Figure $7 \mathrm{H}$ ), while protein levels of other inflammatory and growth factors had returned to levels similar to those found in control eyes (Figure 6). At 18 months p.i., protein level of CCL5 were significantly elevated in eyes of latently infected mice, compared to age matched control eyes or compared to eyes from latently infected mice at earlier time points (4 or 8 months p.i.) (Figure 7A). Interestingly, protein levels of CCL5 were significantly elevated in 18 month old aged control eyes, compared to 4 or 8 month old control eyes. Although relative levels of the $45 \mathrm{KD}$ inactive form of TGF- $\beta 1$ (Figure 6A, 6B) was significantly increased in eyes of latently infected mice at 18 months p.i compared to controls, protein levels of the active forms of TGF- $\beta 1$ including both the $25 \mathrm{KD}$ dimer and $12 \mathrm{KD}$ monomer (Figure 6A, 6B) as well as TGF- $\beta$ receptors including TGF- $\beta$ R1 and TGF- $\beta$ R2 (Figure 6C, 6D) were significantly lower in latently infected eyes compared to age-matched control eyes. In contrast, IL6 protein levels were significantly elevated in 18 month old latently infected eyes compared to age-matched control eyes (Figure 7B).

\section{Discussion}

Several studies have shown that MCMV can initiate latent ocular infection following intraocular inoculation 22,40-42. However, there have been conflicting reports regarding whether MCMV can undergo ocular latency following systemic infection, with several studies reporting that immunosuppression is required for intraocular viral replication after systemic MCMV infection $23,43,44$ while others have reported that MCMV DNA could not be detected within eye tissues of immunocompetent adult C57BL/ 6 mice several months post systemic MCMV infection ${ }^{20}$. A study by Bale et al. reported that latent ocular MCMV could be detected in $10 \%$ of mice infected with MCMV via the intraperitoneal route ${ }^{45}$ while a recent study from Voigt et al. ${ }^{46}$ showed that MCMV spread to the eye following i.p. inoculation of adult BALB/c mice with $1 \times 10^{4} \mathrm{PFU}$, resulting in latent infection in both the iris $(26 \%)$ and choroid $(22 \%)$. The results presented here demonstrate that, following i.p. inoculation of a low dose of MCMV (50 pfu), virus disseminated to the eyes of mice infected at various ages although host response to the virus and the characteristics of subsequent virus persistence varied depending on age at inoculation. Specifically, MCMV underwent ocular latency only in mice infected very early in life. In mice which received MCMV at $<3$ days after birth, MCMV DNA was present in eyes of all mice several months p.i. and latent virus could be reactivated in vitro from 11 of 12 posterior eye cups, which included the choroid and RPE. Likewise, latent MCMV could also be reactivated in vivo in the choroid/RPE of neonatally infected mice following systemic immunosuppression.

Virus-induced disruption of an immature outer blood-retina barrier (BRB) and weak anti-virus immunity 47 in neonatal mice could contribute to the establishment of MCMV latency in the choroid/RPE of almost all mice which were infected early in life. Systemic MCMV disseminated not only to the choroidal endothelia but also passed through the outer blood-retina barrier and infected pericytes and RPE cells in the majority of neonatally-infected mice, although the barrier appeared intact when viewed electron microscopically. The eye is an immune privileged site in which inflammatory responses are limited in order to minimize the risk to vision integrity ${ }^{48-52}$. RPE cells play an important role in this phenomenon by producing 
immunosuppressive factors such as TGF- $\beta$, alpha-melanocyte-stimulating hormone (a-MSH) and vasoactive intestinal peptide ${ }^{48-51}$ as well as by inhibiting immune $T$ cells and converting $T$ cells to regulatory (Treg) cells ${ }^{52}$. Therefore, the immunosuppressive ocular microenvironment around the choroid and RPE could also facilitate the establishment of MCMV latency there.

Many patholgies and abnormalities observed following prolonged MCMV ocular latency are similar to those observed in AMD, a progressive degenerative disease and the leading cause of severe, permanent vision loss in people over age $60^{1-3}$. Although the exact events which contribute to the development of AMD remain uncertain, studies have implicated immunological and inflammatory mechanisms ${ }^{53-55}$ with various clinical and genetic data supporting a tight association between chronic low-grade inflammation and the pathogenesis of AMD ${ }^{56,57}$. Although AMD models in mice, rats, rabbits, pigs and non-human primates have recreated many of the histological features of the disease and provided much insight into its underlying pathological mechanisms; there is currently no single animal model in which all of the characteristics of AMD develop in a progressive manner ${ }^{53,54,58}$.

MCMV latency in the choroid and RPE cells of neonatally-infected BALB/c mice is associated with expression of virus immediate early genes including IE1 and IE3 in the absence of de novo viral protein synthesis. Major immediate-early enhancer (MIE) activity alone does not guarantee full virus reactivation and production of progeny virus ${ }^{37}$, since ectopic expression of the IE proteins is not sufficient to drive viral genome synthesis or infectious progeny production in infected cells ${ }^{36}$. Nevertheless IE expression does modulate the cellular environment as well as the transactivation of early virus genes ${ }^{37}$. For instance, it has been reported that, HCMV IE1 can trigger a proinflammatory host transcriptional response via a STAT1-dependent mechanism ${ }^{38,39}$. In our experiments, expression of IE genes in latently infected eyes was associated with increased transcription and protein production of several inflammatory/angiogenic factors, including CCL5, at all 3 time points studied. CCL5 is produced by platelets and other cells including macrophages, eosinophils, fibroblasts, endothelium, epithelium and endometrial cells ${ }^{59}$. This chemokine participates in multiple biological processes, from pathogen control to enhancement of inflammation ${ }^{59}$ and angiogenesis ${ }^{60}$. Previous studies have suggested that CCL5, which is produced by human RPE cells following chronic inflammatory stimulation, could play an important role in the development of $A M D$ via interactions with $C C R 3^{61}$. A recent studies demonstrated that patients with $\mathrm{GA}$ have a higher plasma levels of CCL-5 and a higher expression of CCR5 in peripheral blood mononuclear cells than healthy controls ${ }^{62}$. Therefore CCL5 production during MCMV ocular latency might contribute to the development of AMD-like pathology.

In summary, the results presented herein demonstrate for the first time that systemic MCMV infection of $\mathrm{BALB} / \mathrm{c}$ mice can spread to the eye with subsequent establishment of latency at the choroid and RPE when infection is acquired early in life. MCMV latency in the choroid/RPE of BALB/c mice was associated with the upregulation of inflammatory/angiogenic factors and most importantly, the development of AMD-like pathology in a progressive manner, including deposits in both basal and apical aspects of the RPE, severe photoreceptor degeneration and eventually, CNV in later life. Therefore, we propose that 
systemic neonatal MCMV infection of BALB/c mice may represent a useful model in which to study these pathologies which are typical of AMD, particularly since the time course of virus-induced pathologies is relatively prolonged, mimicking the situation in human AMD development. This should allow for a more precise dissection of early and late events which eventually culminate in CNV. We have recently demonstrated the presence of HCMV DNA in the choroid/RPE, of approximately $17 \%$ of a group of human cadavers ${ }^{18}$, consistent with latent infection. It is possible that $\mathrm{CMV}$ latency could therefore be a risk factor for the occurrence and development of AMD.

\section{Methods}

Cells and virus. MCMV strain K181 was originally provided by Dr. Edward Morcarski, Emory University, Atlanta, GA. Virus was prepared from the salivary glands of MCMV-infected immunosuppressed BALB/C mice and virus stocks were titered on monolayers of mouse embryo fibroblast (MEF) cells as described previously ${ }^{63}$. A fresh aliquot of virus stocks was thawed and diluted to the appropriate concentration for each experiment.

Mice. Breeding pairs of BALB/c mice were purchased from Jackson Laboratory (Bar Harbor, ME). All mice were given unrestricted access to food and water and were maintained on a 12-hour light cycle alternating with a 12-hour dark cycle. Anesthesia protocols have been described previously ${ }^{64}$. The breeding and treatment of animals in this study adhered to the ARVO Statement for the Use of Animals in Ophthalmic and Vision Research and was approved by the Institutional Animal Care and Use Committee of Augusta University. The rd8 mutation was excluded by genotyping.

Antibodies. Anti-MCMV early antigen (EA) ${ }^{65}$ was labeled with FITC (Sigma-Aldrich, St. Louis, MO) as previously described ${ }^{66}$. Anti-RPE65 was kindly provided by Dr. Michael Redmond (National Eye Institute, National Institutes of Health, Bethesda, MD). Other antibodies used in this study were obtained from the following sources: Rabbit anti-mouse TGF- $\beta$ antibody (\#3711), rabbit anti-mouse TGF- $\beta$-R2 antibody (\#79424) and mouse anti-mouse $\beta$-actin antibody (\#3700) were all from Cell Signaling Technology, Inc. (Danvers, MA, USA). Rabbit anti-mouse TGF- $\beta$-R1 antibody (ab31013) and rabbit anti-mouse Angiopoietin 1 antibody (ab8451) were from Abcam (Cambridge, United Kingdom). Goat anti rabbit IgG HRP (sc2004) and Rabbit anti-goat IgG HRP (sc2768) was from Santa Cruz (Santa Cruz Biotechnology, CA, USA). AntiMouse IgG HRP Conjugate (W402B) was from Promega (Madison WI, USA). Anti-mouse Alexa 488, antirabbit Alexa 594, and Texas red-labeled avidin were from Vector Laboratories, Inc. (Burlingame, CA, USA).

Experimental Design. To determine if acquiring cytomegalovirus infection early in life is associated with widespread virus dissemination and latency at sites including the eye, $50 \mathrm{pfu}$ of MCMV or culture medium as control were injected i.p. into BALB/c mice at either $<3$ days, 1 week, 2 weeks or 6 weeks after birth. At days 14 and 90 post infection (p.i.), mice were euthanized and eyes and extraocular tissues, including salivary glands, lungs and brain, were collected for analysis by plaque assay to quantify 
replicating virus. Viral gene transcription was analyzed by RT-PCR, while MCMV early antigen (EA) expression was analyzed by immunofluorescence staining or by immunogold electron microscopy.

For all other experiments, 50 pfu of MCMV or culture medium as control were i.p. injected into BALB/C mice at $<3$ days p.i. To determine the location of ocular latent infection, some eyes were removed at 3 months p.i., and posterior eye-cups (consisting of RPE, choroid, and sclera) were separated and cultured as described below. To determine if latent ocular infection was associated with ocular pathological changes, eyes were collected from latently infected BALB/c and control mice at 4 and 8 months p.i., and ocular ultrastructure was studied by $\mathrm{H} \& \mathrm{E}$ staining and electron microscopy. To determine if latent ocular infection was accompanied by expression of MCMV immediate early genes and inflammatory/angiogenetic factors, eyes were collected from latently infected BALB/c and control mice at 4, 8, 18 months p.i., and expression of the MCMV IE1, IE3 and gB genes as well as inflammatory/angiogenetic factors, was analyzed by real time RT-PCR. Protein expression of inflammatory/angiogenetic factors was measured by ELISA and Western blot.

To trigger MCMV reactivation, latently infected mice were divided into three groups at 3 months p.i. when replicating virus is no longer recoverable from any ocular or non-ocular site. Mice in group 1 were injected with methylprednisolone acetate, $(2 \mathrm{mg} / \mathrm{mouse}$, i.m., every 3 days) and T cell specific antibodies $(0.45 \mathrm{mg}$ of anti-CD4 [GK1.5] and $0.1 \mathrm{mg}$ of anti-CD8 [2.43], i.v.,1 and 7 days after beginning treatment with methylprednisolone). Mice in group 2 were i.p. injected with lipopolysaccharide (LPS, Sigma, 50 $\mu \mathrm{g} /$ mouse) 7 days after mice in group 1 were treated with methylprednisolone. Mice in group 3 were injected with PBS only. Animals were anesthetized 2 weeks after initiation of immunosuppression or LPS treatment and blood was collected by cardiac puncture using EDTA as an anti-coagulant. Peripheral blood leukocytes (PBL) were separated from blood using ACK Lysing Buffer (Fisher Scientific, Asheville, NC) according to the manufacturer's instructions and viral gene expression was analyzed by RT-PCR.. Eyes, salivary glands and lungs were collected for analysis by plaque assay, RT-PCR, immunofluorescence staining and hematoxylin and eosin (H\&E) staining.

Posterior eye-cup culture. The method of posterior eye-cup culture has been previously described by our laboratory ${ }^{67}$. Eyes were collected from MCMV latently infected mice and the posterior eye cup, consisting of sclera, choroid, and a monolayer of RPE was isolated.. The posterior eyecup was attached to a sterile membrane filter (Schleicher \& Schuell, Dassel, Germany) with the sclera side in contact with the filter and mounted on a coverslip (Nalge Nunc international, Rochester, NY) with Matrigel (BD Biosciences, Bedford, MA). The coverslip with attached eye-cup was inserted in a culture tube in $1 \mathrm{ml}$ of culture medium (DMEM, $10 \% \mathrm{FBS}$ ) and cultured in a roller incubator at $37^{\circ} \mathrm{C}$ with a rotation rate of $10-15 \mathrm{rpm}$. Culture medium was collected after 1 day and twice weekly thereafter and examined by plaque assay for replicating virus. Cultures were also harvested and stained for MCMV EA as described below.

SD-OCT examinations and measurement of retinal thickness. Mice were anesthetized and SD-OCT was performed using the Bioptigen Spectral-Domain Ophthalmic Imaging System (Envisu R2200; Bioptigen, Morrisville, NC, USA) as described previously ${ }^{18,64}$. Briefly, pupils were dilated with $1 \%$ tropicamide and 
systane ultra lubricant eye drop was applied liberally to keep the eye moist during imaging. Images, including averaged single B scan and volume intensity scans (VIP) were acquired. A total of 3 scanning images were acquired from the center of the optic nerve head, the left sphere of the eye (from optic nerve head to left iris), and the right sphere of the eye (from optic nerve to right iris) in each mouse. The highly reflective $\mathrm{CNV}$ lesions located above the RPE layer were quantitated followed by measurement of and total retinal thickness was measured in the scanning image taken from the center of the optic nerve head by using InVivoVue ${ }^{\mathrm{TM}}$ Diver 2.4 software (Bioptigen).

Immunofluorescence staining. Eyes were embedded in OCT compound, frozen and sectioned in a cryostat. Sections were then fixed with $4 \%$ paraformaldehyde for 15 minutes and stained for MCMV EA and/or RPE-65, CD45, IBA-1, CD11b, DX-5 and CD11C as described previously 22,66.

Electron Microscopy and Immunogold Staining. As previously described by our laboratory ${ }^{67,68}$, eyes of MCMV-infected and control mice were fixed (4\% paraformaldehyde, $0.5 \%$ glutaraldehyde in $0.1 \mathrm{M}$ cacodylate buffer) overnight at $4^{\circ} \mathrm{C}$. After washing, dehydrating, and embedding, ultrathin sections were cut and stained with uranyl acetate and lead citrate and visualized in a JEM 1230 transmission electron microscope (JEOL USA Inc., Peabody, MA) at $110 \mathrm{kV}$ and imaged with an UltraScan 4000 CCD camera \& First Light Digital Camera Controller (Gatan Inc., Pleasanton, CA). For immunogold staining ${ }^{67}$, additional ultrathin sections were cut and collected on 200 mesh nickel grids. Following etching with $2 \% \mathrm{H}_{2} \mathrm{O} \otimes$ for 20 minutes, and treatment with $1 \mathrm{M}$ ammonium chloride for 1 hour, sections were blocked with $0.1 \% \mathrm{BSA}$ in PBS for 2-4 hours and floated in anti-MCMV EA antibody overnight at $4^{\circ} \mathrm{C}$. After washing, anti-mouse IgG nanogold was added for 2 hours at room temperature and nanogold particles were enhanced for 3-8 minutes with silver enhancement solution (HQ Silver Enhancement kit, Nanoprobes, Yaphank, NY). Following washing, grids were stained with $2 \%$ uranyl acetate in $70 \% \mathrm{EtoH}$ and lead citrate and visualized in a JEM 1230 transmission electron microscope.

Nucleic acid purification. DNA was extracted from eyes, salivary glands, lungs and peripheral blood leukocytes by overnight digestion with Proteinase $\mathrm{K}$ at $56^{\circ} \mathrm{C}$ with continuous vigorous mixing, followed by centrifugation. The supernatant, was removed and DNA precipitated with an equal volume of isopropanol prior to resuspension in water. Genomic DNA was diluted to $50 \mathrm{ng} / \mu \mathrm{l}$ prior to use. Total RNA was extracted from eyes, salivary glands, lungs and peripheral blood leukocytes using the RNeasy mini Kit (Qiagen, Hilden, Germany) according to the manufacturer's instructions. Reverse transcription (RT) of mRNA was performed on $500 \mathrm{ng}$ of total RNA using the gDNA Clear cDNA Synthesis Kit (Bio-Rad, Hercules, CA) according to the manufactures' instructions. DNA and cDNA were stored at $-80^{\circ} \mathrm{C}$ until use.

PCR, RT-PCR and Real time PCR. All primer sequences are shown in supplemental Table 2. The MCMV IE1 gene was amplified in a $25 \mu$ reaction consisting of $0.1 \mu$ l Taq DNA polymerase (Sigma-Aldrich, U.S.A), $0.4 \mu \mathrm{l}$ of $20 \mathrm{pmol} / \mu \mathrm{l}$ primer mixture, $12.5 \mu \mathrm{L}$ of a $2 \times P C R$ buffer and $1 \mu \mathrm{l}$ of $50 \mathrm{ng} / \mu \mathrm{l}$ DNA. Reaction conditions were $5 \mathrm{~min}, 95^{\circ} \mathrm{C}$ followed by 40 cycles of $95^{\circ} \mathrm{C}, 10 \mathrm{~s}, 60^{\circ} \mathrm{C}, 20 \mathrm{~s}$ and $72^{\circ} \mathrm{C}, 30 \mathrm{~s}$, followed by a final elongation of $5 \mathrm{~min}$ at $72^{\circ} \mathrm{C}$. Amplification products were separated on $1.5 \%$ agarose gels and stained with ethidium bromide. Each real time PCR or RT-PCR $20 \mu \mathrm{l}$ reaction consisted of $10 \mu \mathrm{l} 2 \times$ SYBR 
Mix (Bio-Rad), $0.2 \mu \mathrm{l}$ of $20 \mathrm{pmol} / \mu \mathrm{l}$ primer mixture and $1 \mu \mathrm{l}$ of DNA or cDNA prepared by reverse transcription (RT) of mRNA using $500 \mathrm{ng}$ of total RNA. Reaction conditions were $5 \mathrm{~min}$ at $95^{\circ} \mathrm{C}$ followed by 40 cycles of $95^{\circ} \mathrm{C}, 15 \mathrm{~s}, 60^{\circ} \mathrm{C}, 20 \mathrm{~s}$ and $72^{\circ} \mathrm{C}, 20 \mathrm{~s}$. Amplifications were analyzed by CFX Maestro ${ }^{\mathrm{TM}}$ Software (Bio-rad) and all data were normalized to $\beta$-actin using the method of $2^{-\Delta \Delta C T}$.

Western Blot. Eyes were harvested and lenses removed with the remaining eye tissues homogenized in a lysis buffer containing protease inhibitors (Complete ${ }^{\mathrm{TM}}$ Lysis-M, Roche, Germany). Proteins were extracted as previously described ${ }^{69,70}$ Equal amounts of protein were separated by $10 \%$ or $12 \%$ SDS-PAGE, followed by electroblotting onto polyvinylidene difluoride membranes (Amersham Biosciences, Amersham, UK). Following blocking with $5 \%$ nonfat dry milk for 1 hour at room temperature, membranes were incubated overnight at $4^{0} \mathrm{C}$ with primary antibody.

Binding of HRP-conjugated secondary antibody was performed for 1 hour at room temperature and bands were visualized using chemiluminescence (ECL; GE Healthcare, Chicago, IL). To verify equal loading, membranes were stained with anti- $\beta$-actin and band density was analyzed using Image $\mathrm{J}$ software (NIH, USA).

ELISA. Eyes were collected and homogenized in NP40 lysis buffer (ThermoFisher, Pittsburgh, PA) with 1 mM PMSF and protease inhibitor cocktail (Roche, Germany). The levels of VEGF-A, CCL5 and IL-6 in the tissue lysate were measured by using an ELISA assay kit (R\&D Systems) according to the manufacturer's instructions.

Statistical Analysis. All data were expressed as means \pm SEM, with $n$ representing the number of mice used in each of the experimental groups. Statistical analyses were used to determine the significance of observed differences between treatment groups in all experiments. Statistical significance was calculated by means of two-tailed, unpaired, noparametric, Mann-Whitney test using GraphPad Prism 8 software. P values $<0.05$ were considered to be significant.

\section{References}

1 Bowes Rickman, C., Farsiu, S., Toth, C. A. \& Klingeborn, M. Dry age-related macular degeneration: mechanisms, therapeutic targets, and imaging. Investigative ophthalmology \& visual science 54 , ORSF6880, doi:10.1167/iovs.13-12757 (2013).

2 Bird, A. C. Therapeutic targets in age-related macular disease. The Journal of clinical investigation 120, 3033-3041, doi:10.1172/JCl42437 (2010).

3 Gorin, M. B. Genetic insights into age-related macular degeneration: controversies addressing risk, causality, and therapeutics. Mol Aspects Med 33, 467-486, doi:10.1016/j.mam.2012.04.004 (2012).

4 Boyer, D. S., Schmidt-Erfurth, U., van Lookeren Campagne, M., Henry, E. C. \& Brittain, C. The Pathophysiology of Geographic Atrophy Secondary to Age-Related Macular Degeneration and the 
Complement Pathway as a Therapeutic Target. Retina 37, 819-835, doi:10.1097/IAE.0000000000001392 (2017).

5 Danis, R. P., Lavine, J. A. \& Domalpally, A. Geographic atrophy in patients with advanced dry agerelated macular degeneration: current challenges and future prospects. Clin Ophthalmo/ 9, 2159-2174, doi:10.2147/OPTH.S92359 (2015).

6 Kaszubski, P., Ben Ami, T., Saade, C. \& Smith, R. T. Geographic Atrophy and Choroidal Neovascularization in the Same Eye: A Review. Ophthalmic research 55, 185-193, doi:10.1159/000443209 (2016).

7 Demmler, G. J. Infectious Diseases Society of America and Centers for Disease Control. Summary of a workshop on surveillance for congenital cytomegalovirus disease. Rev Infect Dis 13, 315-329 (1991).

8 Presti, R. M., Pollock, J. L., Dal Canto, A. J., O'Guin, A. K. \& Virgin, H. W. t. Interferon gamma regulates acute and latent murine cytomegalovirus infection and chronic disease of the great vessels. $J$ Exp Med 188, 577-588 (1998).

9 Dupont, L. \& Reeves, M. B. Cytomegalovirus latency and reactivation: recent insights into an age old problem. Rev Med Viro/ 26, 75-89, doi:10.1002/rmv.1862 (2016).

10 Pass, R. F., Stagno, S., Myers, G. J. \& Alford, C. A. Outcome of symptomatic congenital cytomegalovirus infection: results of long-term longitudinal follow-up. Pediatrics 66, 758-762 (1980).

11 Leinikki, P., Granstrom, M. L., Santavuori, P. \& Pettay, O. Epidemiology of cytomegalovirus infections during pregnancy and infancy. A prospective study. Scandinavian journal of infectious diseases 10, 165-171 (1978).

12 Hanshaw, J. B. Congenital cytomegalovirus infection: a fifteen year perspective. The Journal of infectious diseases 123, 555-561 (1971).

13 Lanzieri, T. M. et al. Seroprevalence of cytomegalovirus among children 1 to 5 years of age in the United States from the National Health and Nutrition Examination Survey of 2011 to 2012. Clin Vaccine Immuno/ 22, 245-247, doi:10.1128/CVI.00697-14 (2015).

14 Simon, A. K., Hollander, G. A. \& McMichael, A. Evolution of the immune system in humans from infancy to old age. Proc Biol Sci 282, 20143085, doi:10.1098/rspb.2014.3085 (2015).

15 Boppana, S. et al. Late onset and reactivation of chorioretinitis in children with congenital cytomegalovirus infection. Pediatr Infect Dis J 13, 1139-1142 (1994).

16 Istas, A. S., Demmler, G. J., Dobbins, J. G. \& Stewart, J. A. Surveillance for congenital cytomegalovirus disease: a report from the National Congenital Cytomegalovirus Disease Registry. 
Clinical infectious diseases : an official publication of the Infectious Diseases Society of America 20, 665670 (1995).

17 Stagno, S., Pass, R. F., Dworsky, M. E. \& Alford, C. A. Congenital and perinatal cytomegalovirus infections. Semin Perinatol 7, 31-42 (1983).

$18 \mathrm{Xu}, \mathrm{J}$. et al. Ocular cytomegalovirus latency exacerbates the development of choroidal neovascularization. The Journal of pathology 251, 200-212, doi:10.1002/path.5447 (2020).

19 Miller, D. M. et al. The association of prior cytomegalovirus infection with neovascular age-related macular degeneration. American journal of ophthalmology 138, 323-328, doi:10.1016/j.ajo.2004.03.018 (2004).

20 Cousins, S. W. et al. Macrophage activation associated with chronic murine cytomegalovirus infection results in more severe experimental choroidal neovascularization. PLoS pathogens 8, e1002671, doi:10.1371/journal.ppat.1002671 (2012).

21 Fernandez-Godino, R., Garland, D. L. \& Pierce, E. A. Isolation, culture and characterization of primary mouse RPE cells. Nat Protoc 11, 1206-1218, doi:10.1038/nprot.2016.065 (2016).

22 Zhang, M., Xin, H., Duan, Y. \& Atherton, S. S. Ocular reactivation of MCMV after immunosuppression of latently infected BALB/c mice. Invest Ophthalmol Vis Sci 46, 252-258, doi:10.1167/iovs.04-0537 (2005).

23 Zhang, M., Xin, H. \& Atherton, S. S. Murine cytomegalovirus (MCMV) spreads to and replicates in the retina after endotoxin-induced disruption of the blood-retinal barrier of immunosuppressed BALB/C mice. Journal of neurovirology 11, 365-375, doi:10.1080/13550280591002432 (2005).

24 Huang, D. et al. Optical coherence tomography. Science 254, 1178-1181 (1991).

25 Drexler, W. et al. Ultrahigh-resolution ophthalmic optical coherence tomography. Nat Med 7, 502507, doi:10.1038/86589 (2001).

26 Curcio, C. A. Soft Drusen in Age-Related Macular Degeneration: Biology and Targeting Via the Oil Spill Strategies. Investigative ophthalmology \& visual science 59, AMD160-AMD181, doi:10.1167/iovs.1824882 (2018).

27 Spaide, R. F., Ooto, S. \& Curcio, C. A. Subretinal drusenoid deposits AKA pseudodrusen. Surv Ophthalmo/ 63, 782-815, doi:10.1016/j.survophthal.2018.05.005 (2018).

28 Rabiolo, A. et al. Spotlight on reticular pseudodrusen. Clin Ophthalmo/ 11, 1707-1718, doi:10.2147/OPTH.S130165 (2017). 
29 Wills, M. R., Poole, E., Lau, B., Krishna, B. \& Sinclair, J. H. The immunology of human cytomegalovirus latency: could latent infection be cleared by novel immunotherapeutic strategies? Cell Mol Immunol 12, 128-138, doi:10.1038/cmi.2014.75 (2015).

30 Caposio, P., Orloff, S. L. \& Streblow, D. N. The role of cytomegalovirus in angiogenesis. Virus Res 157, 204-211, doi:10.1016/j.virusres.2010.09.011 (2011).

31 Caposio, P. et al. Targeting the NF-kappaB pathway through pharmacological inhibition of IKK2 prevents human cytomegalovirus replication and virus-induced inflammatory response in infected endothelial cells. Antiviral Res 73, 175-184, doi:10.1016/j.antiviral.2006.10.001 (2007).

32 Botto, S. et al. IL-6 in human cytomegalovirus secretome promotes angiogenesis and survival of endothelial cells through the stimulation of survivin. Blood 117, 352-361, doi:10.1182/blood-2010-06291245 (2011).

33 Penfold, M. E. et al. Cytomegalovirus encodes a potent alpha chemokine. Proceedings of the National Academy of Sciences of the United States of America 96, 9839-9844 (1999).

34 Dumortier, J. et al. Human cytomegalovirus secretome contains factors that induce angiogenesis and wound healing. Journal of virology 82, 6524-6535, doi:10.1128/JVI.00502-08 (2008).

35 Maussang, D. et al. The human cytomegalovirus-encoded chemokine receptor US28 promotes angiogenesis and tumor formation via cyclooxygenase-2. Cancer Res 69, 2861-2869, doi:10.1158/00085472.CAN-08-2487 (2009).

36 Yee, L. F., Lin, P. L. \& Stinski, M. F. Ectopic expression of HCMV IE72 and IE86 proteins is sufficient to induce early gene expression but not production of infectious virus in undifferentiated promonocytic THP-1 cells. Virology 363, 174-188, doi:10.1016/j.virol.2007.01.036 (2007).

37 Goodrum, F. Human Cytomegalovirus Latency: Approaching the Gordian Knot. Annu Rev Viro/3, 333-357, doi:10.1146/annurev-virology-110615-042422 (2016).

38 Knoblach, T., Grandel, B., Seiler, J., Nevels, M. \& Paulus, C. Human cytomegalovirus IE1 protein elicits a type II interferon-like host cell response that depends on activated STAT1 but not interferongamma. PLoS pathogens 7, e1002016, doi:10.1371/journal.ppat.1002016 (2011).

39 Reitsma, J. M., Sato, H., Nevels, M., Terhune, S. S. \& Paulus, C. Human cytomegalovirus IE1 protein disrupts interleukin-6 signaling by sequestering STAT3 in the nucleus. Journal of virology $\mathbf{8 7 , 1 0 7 6 3 -}$ 10776, doi:10.1128/JVI.01197-13 (2013).

40 Hayashi, K., Kurihara, I. \& Uchida, Y. Studies of ocular murine cytomegalovirus infection. Investigative ophthalmology \& visual science 26, 486-493 (1985). 
41 Bale, J. F., Jr., O'Neil, M. E., Lyon, B. \& Perlman, S. The pathogenesis of murine cytomegalovirus ocular infection. Anterior chamber inoculation. Investigative ophthalmology \& visual science 31, 15751581 (1990).

42 Kercher, L. \& Mitchell, B. M. Persisting murine cytomegalovirus can reactivate and has unique transcriptional activity in ocular tissue. J Virol 76, 9165-9175 (2002).

43 Gao, E. K., Yu, X. H., Lin, C. P., Zhang, H. \& Kaplan, H. J. Intraocular viral replication after systemic murine cytomegalovirus infection requires immunosuppression. Investigative ophthalmology \& visual science 36, 2322-2327 (1995).

44 Dix, R. D. Systemic murine cytomegalovirus infection of mice with retrovirus-induced immunodeficiency results in ocular infection but not retinitis. Ophthalmic research 30, $295-301$ (1998).

45 Bale, J. F., Jr., O'Neil, M. E., Hogan, R. N. \& Kern, E. R. Experimental murine cytomegalovirus infection of ocular structures. Arch Ophthalmol 102, 1214-1219 (1984).

46 Voigt, V. et al. Cytomegalovirus establishes a latent reservoir and triggers long-lasting inflammation in the eye. PLoS pathogens 14, e1007040, doi:10.1371/journal.ppat.1007040 (2018).

47 van Well, G. T. J., Daalderop, L. A., Wolfs, T. \& Kramer, B. W. Human perinatal immunity in physiological conditions and during infection. Mol Cell Pediatr 4, 4, doi:10.1186/s40348-017-0070-1 (2017).

48 Sugita, S. Role of ocular pigment epithelial cells in immune privilege. Arch Immunol Ther Exp (Warsz) 57, 263-268, doi:10.1007/s00005-009-0030-0 (2009).

49 Keino, H., Horie, S. \& Sugita, S. Immune Privilege and Eye-Derived T-Regulatory Cells. J Immunol Res 2018, 1679197, doi:10.1155/2018/1679197 (2018).

50 Ao, J., Wood, J. P., Chidlow, G., Gillies, M. C. \& Casson, R. J. Retinal pigment epithelium in the pathogenesis of age-related macular degeneration and photobiomodulation as a potential therapy? Clin Exp Ophthalmol 46, 670-686, doi:10.1111/ceo.13121 (2018).

51 Streilein, J. W., Ma, N., Wenkel, H., Ng, T. F. \& Zamiri, P. Immunobiology and privilege of neuronal retina and pigment epithelium transplants. Vision Res 42, 487-495 (2002).

52 Stein-Streilein, J. Immune regulation and the eye. Trends in immunology 29, 548-554, doi:10.1016/j.it.2008.08.002 (2008).

53 Pennesi, M. E., Neuringer, M. \& Courtney, R. J. Animal models of age related macular degeneration. Mol Aspects Med 33, 487-509, doi:10.1016/j.mam.2012.06.003 (2012). 
54 Fletcher, E. L. et al. Studying age-related macular degeneration using animal models. Optom Vis Sci 91, 878-886, doi:10.1097/OPX.0000000000000322 (2014).

55 Ding, J. D. et al. The role of complement dysregulation in AMD mouse models. Adv Exp Med Biol 801, 213-219, doi:10.1007/978-1-4614-3209-8_28 (2014).

56 Copland, D. A., Theodoropoulou, S., Liu, J. \& Dick, A. D. A Perspective of AMD Through the Eyes of Immunology. Investigative ophthalmology \& visual science 59, AMD83-AMD92, doi:10.1167/iovs.1823893 (2018).

57 Buschini, E., Piras, A., Nuzzi, R. \& Vercelli, A. Age related macular degeneration and drusen: neuroinflammation in the retina. Prog Neurobio/ 95, 14-25, doi:10.1016/j.pneurobio.2011.05.011 (2011).

58 Ramkumar, H. L., Zhang, J. \& Chan, C. C. Retinal ultrastructure of murine models of dry age-related macular degeneration (AMD). Prog Retin Eye Res 29, 169-190, doi:10.1016/j.preteyeres.2010.02.002 (2010).

59 Marques, R. E., Guabiraba, R., Russo, R. C. \& Teixeira, M. M. Targeting CCL5 in inflammation. Expert Opin Ther Targets 17, 1439-1460, doi:10.1517/14728222.2013.837886 (2013).

60 Suffee, N. et al. Angiogenic properties of the chemokine RANTES/CCL5. Biochem Soc Trans 39, 1649-1653, doi:10.1042/BST20110651 (2011).

61 Nagineni, C. N. et al. Inflammatory Cytokines Induce Expression of Chemokines by Human Retinal Cells: Role in Chemokine Receptor Mediated Age-related Macular Degeneration. Aging Dis 6, 444-455, doi:10.14336/AD.2015.0323 (2015).

62 Krogh Nielsen, M. et al. Chemokine Profile and the Alterations in CCR5-CCL5 Axis in Geographic Atrophy Secondary to Age-Related Macular Degeneration. Investigative ophthalmology \& visual science 61, 28, doi:10.1167/iovs.61.4.28 (2020).

63 Atherton, S. S., Newell, C. K., Kanter, M. Y. \& Cousins, S. W. T cell depletion increases susceptibility to murine cytomegalovirus retinitis. Investigative ophthalmology \& visual science 33, 3353-3360 (1992).

64 Mo, J. et al. Role of Bax in death of uninfected retinal cells during murine cytomegalovirus (MCMV) retinitis. Invest Ophthalmol Vis Sci, doi:10.1167/iovs.14-15404 (2014).

65 Pande, H. et al. Characterization of a $52 \mathrm{~K}$ protein of murine cytomegalovirus and its immunological cross-reactivity with the DNA-binding protein ICP36 of human cytomegalovirus. $J$ Gen Virol 72 (Pt 6), 1421-1427, doi:10.1099/0022-1317-72-6-1421 (1991).

66 Zhang, M., Xin, H., Roon, P. \& Atherton, S. S. Infection of retinal neurons during murine cytomegalovirus retinitis. Invest Ophthalmol Vis Sci 46, 2047-2055, doi:10.1167/iovs.05-0005 (2005). 
$67 \mathrm{Xu}$, J. et al. Inflammation and outer blood-retina barrier (BRB) compromise following choroidal murine cytomegalovirus (MCMV) infections. Mol Vis 24, 379-394 (2018).

$68 \mathrm{Xu}$, J. et al. Depletion of the Receptor-Interacting Protein Kinase 3 (RIP3) Decreases Photoreceptor Cell Death During the Early Stages of Ocular Murine Cytomegalovirus Infection. Investigative ophthalmology \& visual science 59, 2445-2458, doi:10.1167/iovs.18-24086 (2018).

69 Zhang, M., Covar, J., Marshall, B., Dong, Z. \& Atherton, S. S. Lack of TNF-alpha promotes caspase3-independent apoptosis during murine cytomegalovirus retinitis. Investigative ophthalmology \& visual science 52, 1800-1808, doi:10.1167/iovs.10-6904 (2011).

70 Zhang, M., Marshall, B. \& Atherton, S. S. Murine cytomegalovirus infection and apoptosis in organotypic retinal cultures. Investigative ophthalmology \& visual science 49, 295-303, doi:10.1167/iovs.07-0612 (2008).

\section{Tables}

Table 1. Frequency of MCMV EA detection in various ocular locations

\begin{tabular}{ccccc}
\hline & Choroid & RPE & Sclera & Iris/cliary body \\
\hline Acute infection & $7 / 7$ & $3 / 7$ & $5 / 7$ & $1 / 7$ \\
\hline Reactivation & $6 / 6$ & $2 / 6$ & $6 / 6$ & $6 / 6$ \\
\hline
\end{tabular}

Table 2. Frequency of expression of the MCMV genes in eyes of BALB/c mice at 4, 8, 18 months post neonatal i.p. infection analyzed by real-time RT-PCR

\begin{tabular}{cccc}
\hline Gene Symbol & 4 months & $\mathbf{8}$ months & $\mathbf{1 8}$ months \\
\hline MCMV IE1 & $6 / 9$ & $4 / 6$ & $9 / 11$ \\
\hline MCMV IE3 & $6 / 9$ & $4 / 6$ & $9 / 11$ \\
\hline MCMV GB & $1 / 9$ & $1 / 6$ & $2 / 11$ \\
\hline
\end{tabular}


Table 3. Relative expression levels of inflammatory/angiogenic genes in eyes of MCMV infected mice at 4 months $(n=6), 8$ months $(n=6)$ and 18 months $(n=4)$ p.i. compared to age-matched control eyes $(n=6,6$ and 4 respectively for age 4,8 and 18 months).

\begin{tabular}{|l|l|l|l|}
\hline $\begin{array}{c}\text { Gene } \\
\text { Symbol }\end{array}$ & $\begin{array}{c}\text { 4 months } \\
\text { (p value) }\end{array}$ & $\begin{array}{c}\text { 8 months } \\
(\mathrm{p} \text { value })\end{array}$ & $\begin{array}{c}18 \text { months } \\
(\mathrm{p} \text { value })\end{array}$ \\
\hline TGF- $\beta 1$ & $\begin{array}{c}107.08 \pm 3.20 \\
(0.000)\end{array}$ & $\begin{array}{c}0.76 \pm 0.35 \\
(0.197)\end{array}$ & $\begin{array}{c}1.41 \pm 0.28 \\
(0.308)\end{array}$ \\
\hline Ccl5 & $\begin{array}{c}19.44 \pm 3.10 \\
(0.009)\end{array}$ & $\begin{array}{c}6.91 \pm 2.17 \\
(0.000)\end{array}$ & $\begin{array}{c}5.38 \pm 1.12 \\
(0.019)\end{array}$ \\
\hline Ang1 & $\begin{array}{c}16.72 \pm 3.70 \\
(0.011)\end{array}$ & $\begin{array}{c}1.89 \pm 0.23 \\
(0.160)\end{array}$ & $\begin{array}{c}1.29 \pm 0.17 \\
(0.222)\end{array}$ \\
\hline IL-6 & $\begin{array}{c}3.19 \pm 0.64 \\
(0.024)\end{array}$ & $\begin{array}{c}0.11 \pm 0.03 \\
(0.088)\end{array}$ & $\begin{array}{c}26.97 \pm 8.03 \\
(0.032)\end{array}$ \\
\hline Vegf-a & $\begin{array}{c}3.00 \pm 0.58 \\
(0.012)\end{array}$ & $\begin{array}{c}1.19 \pm 0.07 \\
(0.019)\end{array}$ & $\begin{array}{c}0.54 \pm 0.0 .04 \\
(0.007)\end{array}$ \\
\hline ICAM1 & $\begin{array}{c}2.44 \pm 0.161 \\
(0.001)\end{array}$ & $\begin{array}{c}0.68 \pm 0.32 \\
(0.108)\end{array}$ & $\begin{array}{c}1.46 \pm 0.32 \\
(0.290)\end{array}$ \\
\hline G-csf & $2.28 \pm 0.58$ & $1.30 \pm 0.06$ & $1.11 \pm 0.05$ \\
& $(0.097)$ & $(0.000)$ & $(0.370)$ \\
\hline Ang2 & $1.74 \pm 0.198$ & $1.36 \pm 0.17$ & $0.93 \pm 0.05$ \\
& $(0.023)$ & $(0.017)$ & $(0.505)$ \\
\hline Pdgfb & $1.43 \pm 0.072$ & $1.15 \pm 0.19$ & $1.19 \pm 0.12$ \\
& $(0.012)$ & $(0.311)$ & $(0.513)$ \\
\hline Ccl7 & $0.98 \pm 0.347$ & $0.61 \pm 0.18$ & $3.97 \pm 0.44$ \\
& $(0.962)$ & $(0.058)$ & $(0.004)$ \\
\hline Sdf1 & $0.93 \pm 0.102$ & $1.67 \pm 0.63$ & $1.12 \pm 0.16$ \\
& $(0.574)$ & $(0.048)$ & $(0.632)$ \\
\hline
\end{tabular}

Data are shown as mean \pm SEM and compared by the Mann-Whitney test.

Figures 


\section{Figure 1}
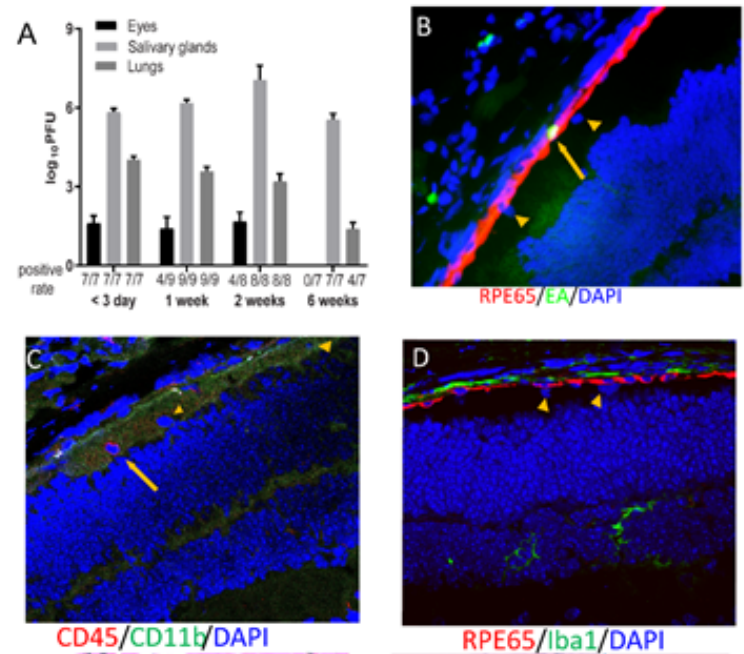

RPE65/Iba1/DAPI
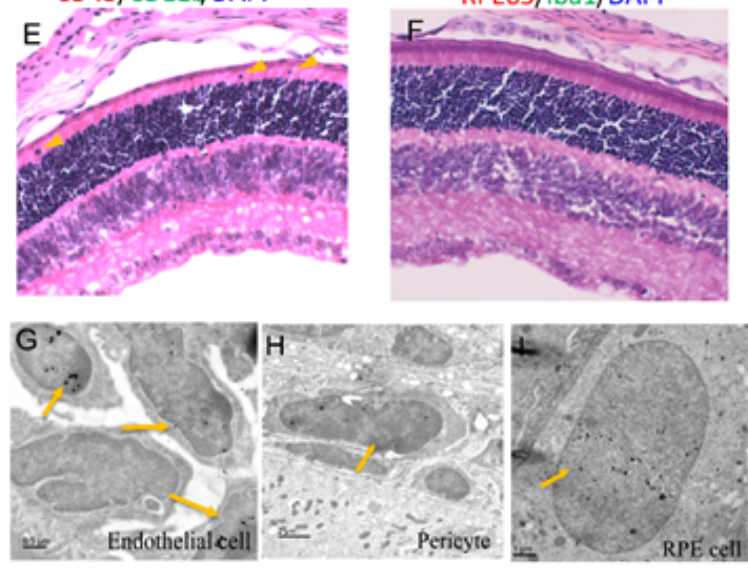

Figure 1. Infection with MCMV in early life results in dissemination of virus to various organs including the eye. (A) Titer of MCMV at day 14 p.i. in eyes, salivary glands and lungs of BALB/c mice. (B) Merged photomicrographs of ocular staining for RPE65 (red), MCMV EA (green), and DAPI (blue) at 14 days p.i following i.p. infection with MCMV at $<3$ days after birth. The majority of MCMV EA positive cells were located in the choroid. A few MCMV infected cells were also observed in the RPE layer (indicated by arrow). Some RPE65-, MCMV EA- infiltrating cells were observed in the photoreceptor layer (indicated by arrowheads). (C) Merged photomicrographs of ocular staining for CD45 (red), CD11b (green), and DAPI (blue) at day 14 p.i following i.p. MCMV infection at $<3$ days after birth. Infiltrating cells in the photoreceptor layer stained negative for CD11b while some stained positive for CD45 (arrow). Cells staining negative for both CD45 and CD11b are indicated by arrowheads. (D) Merged photomicrographs of ocular staining for RPE65 (red), lba1 (green), and DAPI (blue) at day14 p.i following i.p.MCMV infection at $<3$ days after birth Infiltrating cells in the photoreceptor layer stained negative for both RPE65 and lba1. (E, F)

Photomicrographs of ocular $\mathrm{H} \& \mathrm{E}$ staining at day 14 p.i following i.p. infection with MCMV at $<3$ days after birth $(E)$ and in age matched, uninfected control mice $(F)$. Compared to uninfected controls, some infiltrating cells were observed in the photoreceptor layer ( $E$, indicated by arrowheads) but no remarkable pathological changes were observed in the inner retina of MCMV infected mice. (G-I) Immunogold staining with antiMCMV EA showing immunogold-labeled MCMV EA in nuclei of some vascular endothelial cells (A, arrows) and pericytes (B, arrow) in the choriocapillaris, and also in sporadic RPE cells ( $\mathrm{C}$, arrow).

\section{Figure 1}

Fig 1 


\section{Figure 2}
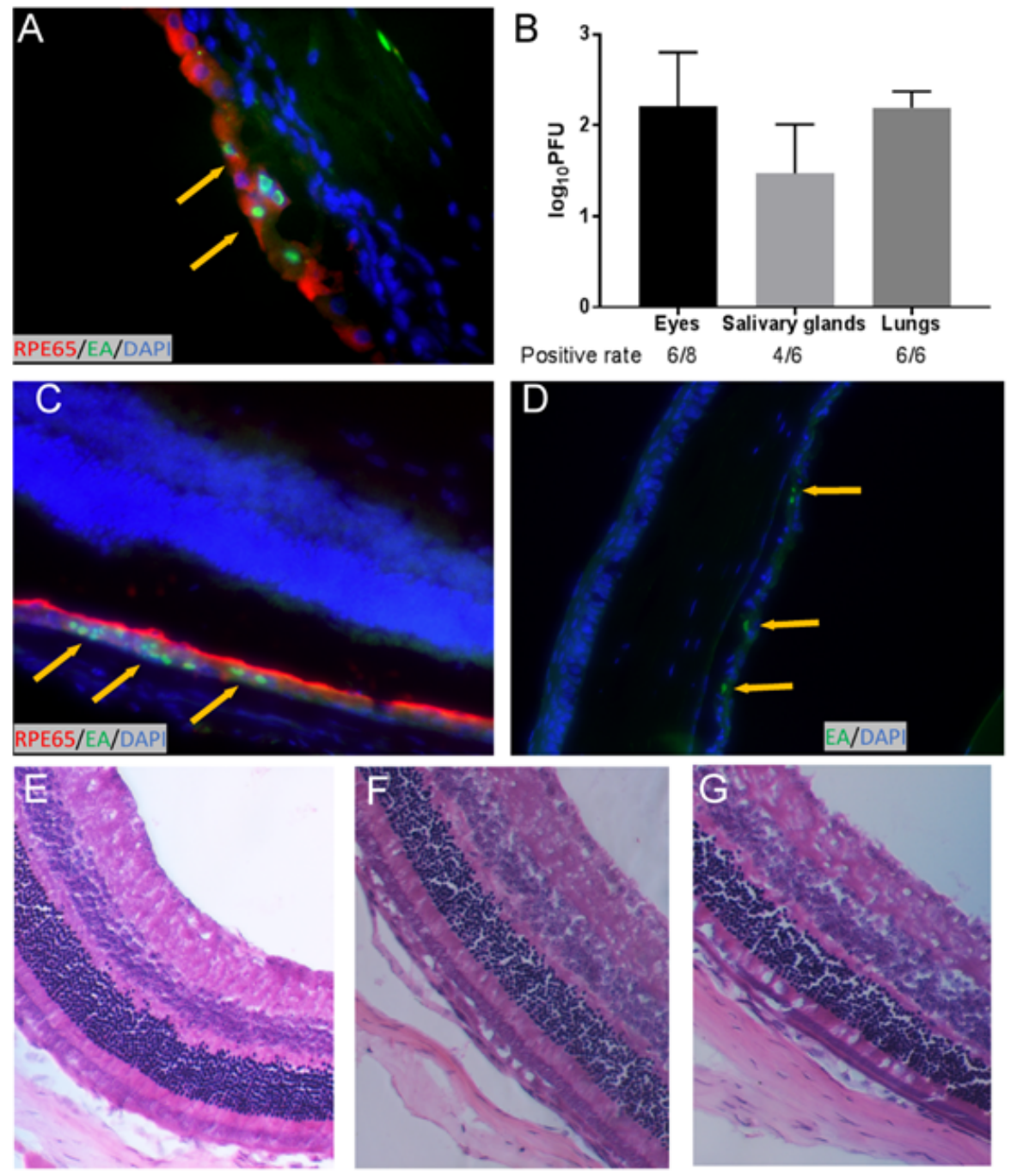

Figure 2. MCMV can be reactivated in vitro and in vivo from eyes of latently infected mice following systemic immunosuppression. (A) Merged photomicrographs of ocular staining for RPE65 (red), MCMV EA (green), and DAPI (blue) in eye cup cultures prepared from BALB/c mice at 4 months post i.p. neonatal infection. MCMV EA was observed in both choroid and RPE (indicated by arrows). (B) Titer of MCMV in eyes, salivary glands and lungs of MCMV latently infected BALB/c mice following systemic immunosuppression for 2 weeks. (C) Merged photomicrographs of ocular staining for RPE65 (red), MCMV EA (green), and DAPI (blue) in eyes of MCMV latently infected mice following systemic immunosuppression for 2 weeks. The majority of MCMV EA-staining cells were observed in the choroid (arrows). (D) Merged photomicrographs of ocular staining for MCMV EA (green) and DAPI (blue) in eyes of MCMV latently infected mice following systemic immunosuppression for 2 weeks. MCMV EA-staining cells were observed in the iris (arrows). (E-G) Photomicrographs of $\mathrm{H} \& \mathrm{E}$ staining in eyes of immunosuppressed MCMV latently infected mice ( $\mathrm{F})$, non-immunosuppressed MCMV latently infected mice $(G)$ and age-matched uninfected controls $(E)$. No remarkable pathological changes were observed in the inner retina.

\section{Figure 2}

Fig 2 


\section{Figure 3}

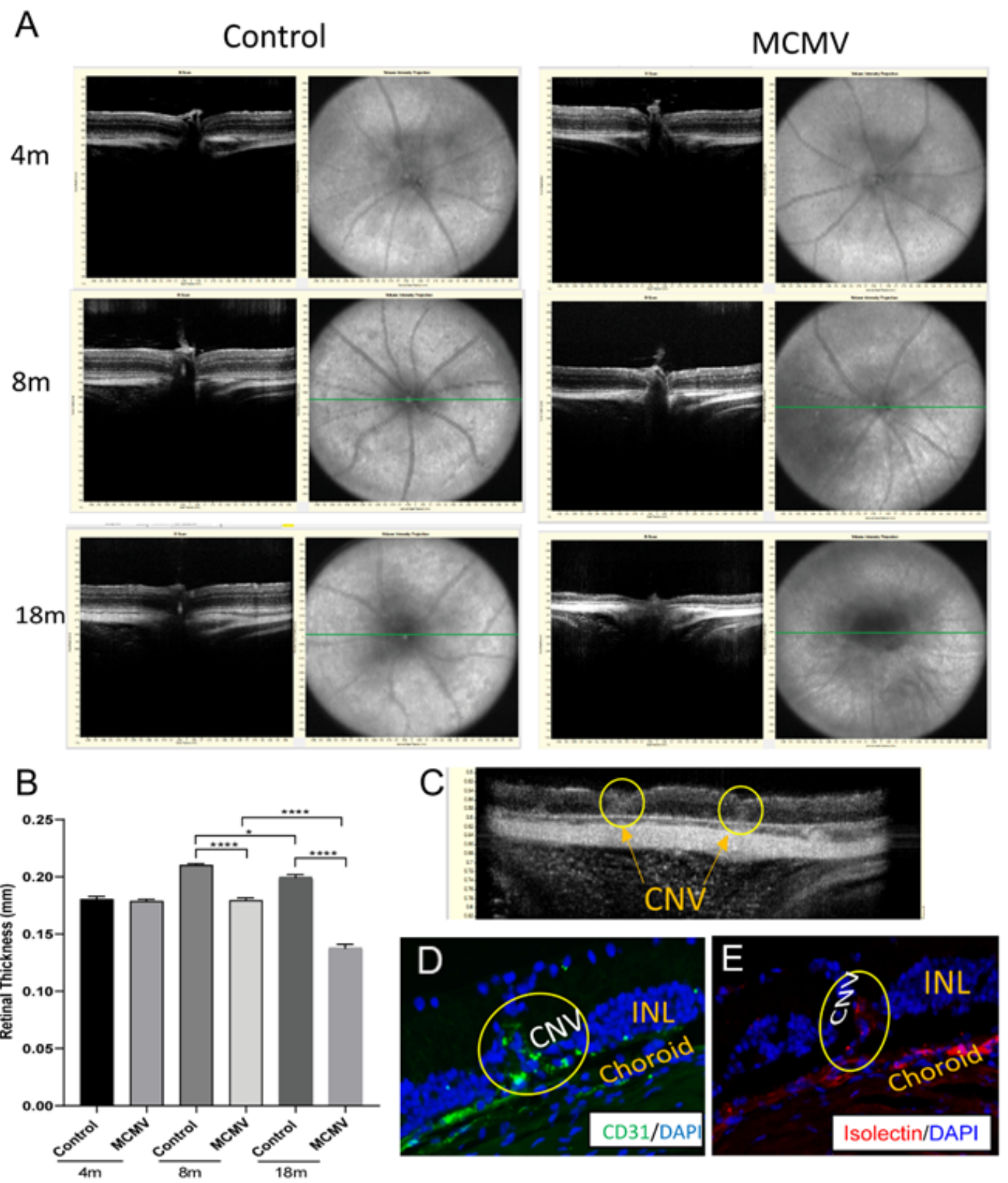

Figure 3. SD-OCT and CNV lesions. (A) Representative images of SD-OCT in eyes of latently infected mice at $4(n=5), 8(n=12), 18(n=40)$ months p.i. and age-matched control eyes $(n=5,12$ and 20

respectively for age 4,8 and 18 months). (B) Retinal thickness by SD-OCT. ${ }^{\star * \star *} p<0.001,{ }^{\star} p<0.05$ by the Mann-Whitney test. (C) CNV-like lesions detected by SD-OCT (circles). (D) Merged photomicrograph of ocular staining for CD31 (green) and DAPI (blue) at 18 months p.i. CD31+ vascular endothelial cells were observed in CNV lesion (circle) (E) Merged photomicrograph of ocular staining for isolectin (red) and DAPI (blue) at 18 months p.i. Isolectin + vascular endothelial cells were observed in CNV lesion (circle).

\section{Figure 3}

Fig 3 


\section{Figure 4}
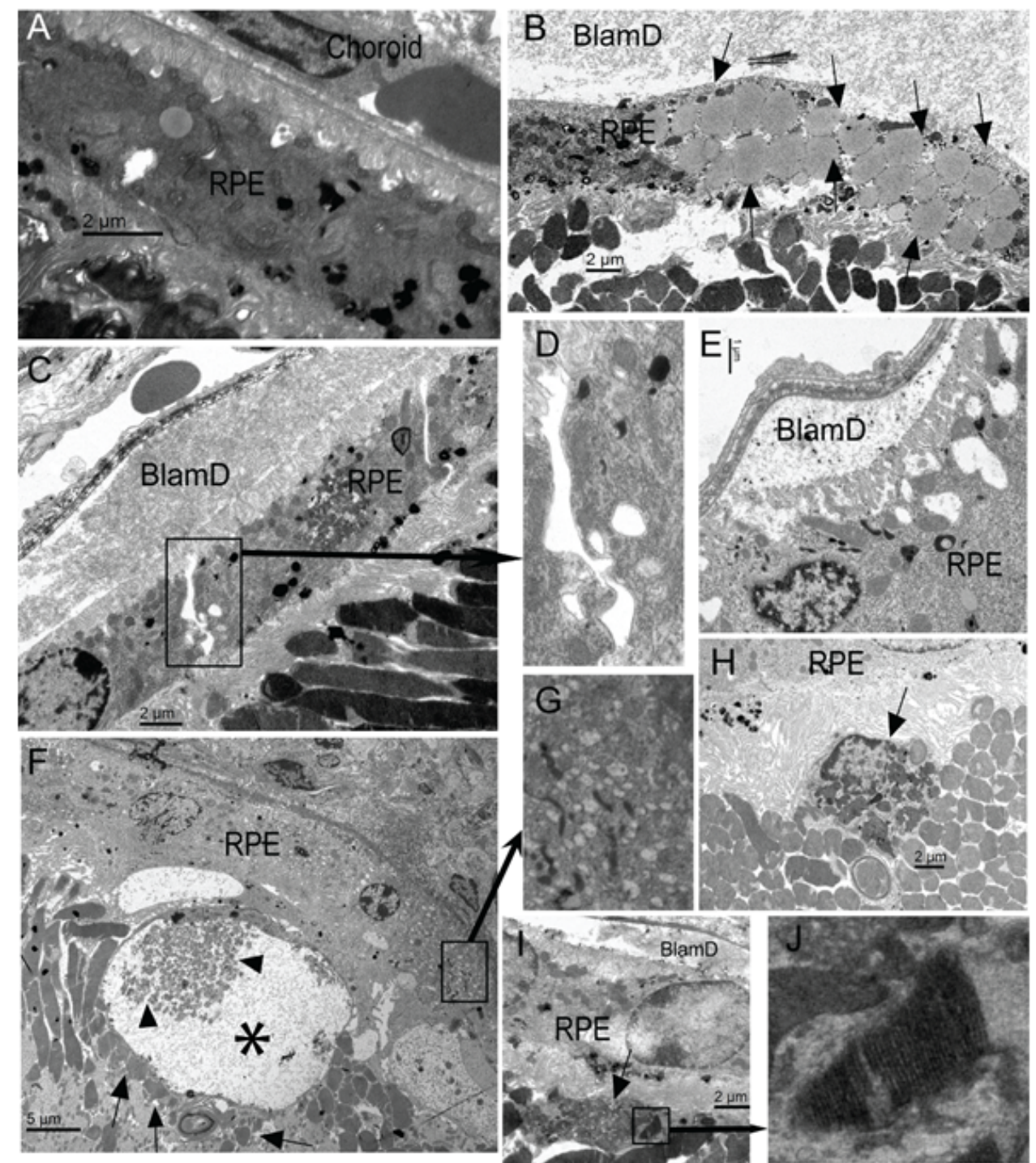

Figure 4. Representative electron micrographs of ocular ultrastructure in 8 months post neonatal i.p. infected (B-J) or age matched uninfected control, BALB/c mice (A). (A) Only occasional lipid vesicles were noted in RPE cells of control mice. (B) Large lipid vesicles inside RPE cells (arrows) and one large diffuse lightly stained BlamD deposit. $(C, D)$ Loss of tight junctions between RPE cells located below one large diffuse BlamD deposit with evacuated areas created between these RPE cells. (E) one diffuse lightly stained BlamD deposit. ( $F, G)$ Some RPE cells exhibited marked vacuolization $(G)$. One large structure $(F$, indicated by star) which contained heterogeneous materials including dark-staining outer segment-like fragments ( $F$, indicated by arrow heads) in the subretinal space adjacent to these atypical RPE cells; nearby photoreceptors exhibited shortening and loss of outer segments ( $F$, indicated by arrows). ( $\mathrm{H}, \mathrm{I}, \mathrm{J})$ Some infiltrating cells were observed in the subretinal space of infected mice $(\mathrm{H}, \mathrm{I}$, indicated by arrows). Dark-staining OS-like fragments were also observed inside some of these cells $(\mathrm{H}, \mathrm{I})$. Discs were occasionally noted among these fragments $(\mathrm{J})$.

\section{Figure 4}

Fig 4 
Figure 5
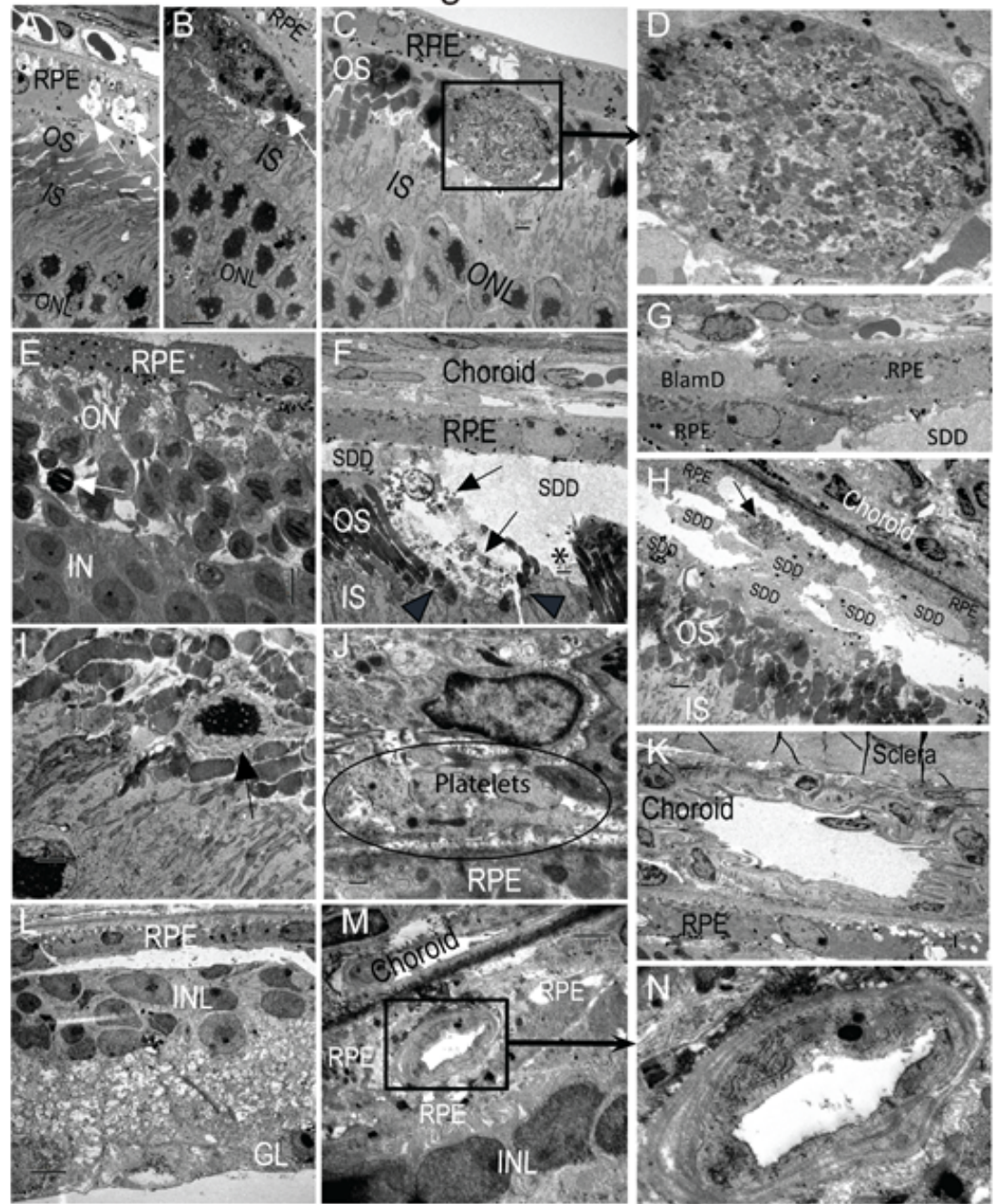

Figure 5. Representative electron micrographs of ocular ultrastructure in 18 months post neonatal i.p. infected (B-M) or age matched uninfected control, BALB/c mice (A). (A, B) Some large lipid vesicles were present in some RPE cells of control eyes (indicated by arrow. Sporadic infiltrating cells were also observed in the subretinal space of control eyes (indicated by arrow). Loss or shortening of OS were noted surrounding the infiltrating cells. (C, D) Infiltrating cells were observed in the subretina of infected mice at 18 months p.i.(C). Dark-staining OS-like fragments were observed inside the cell (D). (E) RPE exhibited marked vacuolization, disappearance of entire OS, IS, and death of photoreceptor cells (arrow) were observed. (F-H) BlamD deposits were observed $(G)$. Some SDD deposits were noted in the subretinal space $(F, G, H)$. Some SDD deposits contained dark-staining OS-like fragments ( $F, H$, indicated by arrows), while others appeared drusen-like and were lightly stained $F, G, H)$. The morphology of nearby photoreceptors was disturbed, with shortening and loss of OS and IS ( $F$, arrow heads). OS were absent in some areas and SDD deposits bulged into the IS layer ( $F$, indicated by star). (I) An ectopic photoreceptor nucleus was noted in the OS layer (indicated by arrow). (J) Extensive choroidal platelet infiltration in perivascular tissue indicated by circle. (K) Lack of choroidal capillaries in some area of choroid. One artery was located between the sclera and BM. (L) Severe retinal degeneration; the entire ONL was absent while the INL was thin and composed of only 3 to 4 layers of cells. (M, N) One CNV lesion in the sub-RPE space; RPE cells were in contact with the INL due to the loss of the entire ONL.

\section{Figure 5}

Fig 5 


\section{Figure 6}

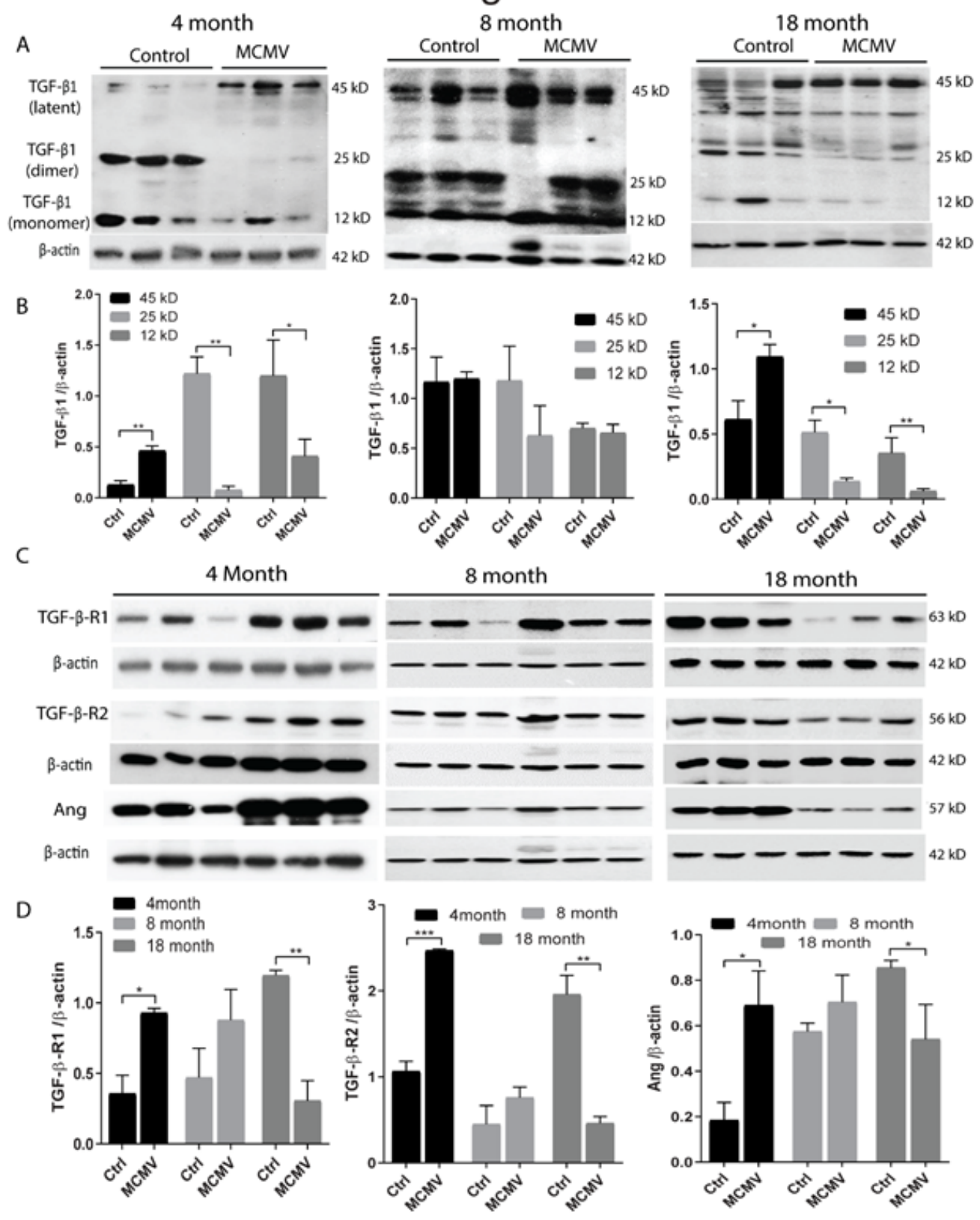

Figure 6. Protein levels of TGF- $\beta 1$, TGF- $\beta-R 1$, TGF- $\beta-R 2$ and angiopoietin I (Ang) analyzed by western blot. (A) Western blots of TGF- $\beta 1$ in eyes of latently infected mice at $4,8,18$ months p.i. and age-matched control eyes. (B) Ratio of TGF- $\beta 1$ to $\beta$-actin. (C) Western blots of TGF- $\beta-R 1$, TGF- $\beta$-R2 and Ang in eyes of latently infected mice at 4, 8, 18 months p.i. and age-matched control eyes. (D) Ratio of TGF- $\beta$-R1, TGF- $\beta$-R2 or Ang to $\beta$-actin. Data are shown as mean \pm SEM $(n=3)$ and compared by the Mann-Whitney test. ${ }^{* \star *} \mathrm{P}<0.001,{ }^{\star *} \mathrm{P}<0.01,{ }^{*} \mathrm{P}<0.05$.

\section{Figure 6}

Fig 6 


\section{Figure 7}
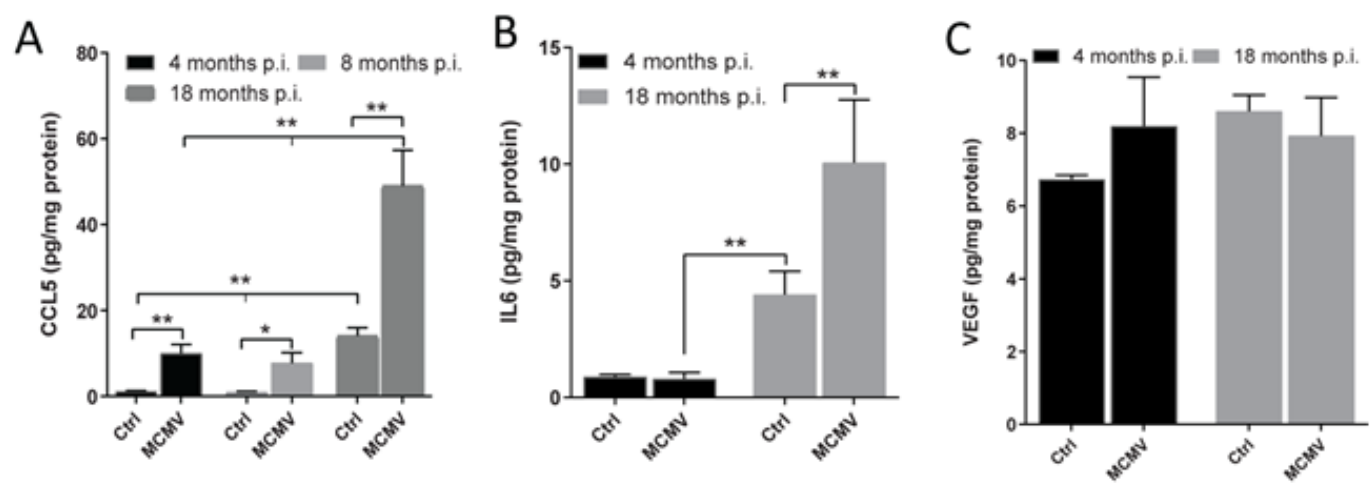

Figure 7. Protein levels of CCL5, IL6 and VEGF. (A). ELISA assay of CCL5 in eyes of latently infected mice at $4(n=4), 8(n=3), 18(n=6)$ months p.i. and age-matched control eyes $(n=4,3$ and 6 respectively for age 4,8 and 18 months). Data are shown as mean \pm SEM. ${ }^{* \star} p<0.01,{ }^{*} p<0.05$, by the Mann-Whitney test. (B, C). ELISA assay of IL6 (B) and VEGF (C) in eyes of latently infected mice at 4 $(n=4)$ and $18(n=6)$ months p.i. and age-matched control eyes $(n=4$ and 6 respectively for age 4 and 18 months). Data are shown as mean \pm SEM. ${ }^{\star \star} p<0.01$, by the Mann-Whitney test.

Figure 7

Fig 7

\section{Supplementary Files}

This is a list of supplementary files associated with this preprint. Click to download. 
- supplementalmaterial.pdf

Page 29/29 